\title{
Transcatheter closure of Blalock-Taussig shunts with a modified Rashkind umbrella delivery
} system

Christine Houde, Evan M Zahn, Lee N Benson

\begin{abstract}
Transcatheter occlusion of Blalock-Taussig shunts was successfully performed in three children with the Rashkind double umbrella occluding device. Complete occlusion was confirmed angiographically in two patients and echocardiographically in the third. The delivery system was adapted for use through smaller sheaths making it more suitable for small children or arterial access.
\end{abstract}

(Br Heart $J$ 1993;69:56-58)

Various devices including steel coils and detachable silicone balloons have been used for transcatheter occlusion of aortopulmonary collaterals, arteriovenous malformations, and surgical systemic to pulmonary shunts. ${ }^{1}$ The procedure requires precision and even in experienced hands can lead to inadvertent distal systemic and pulmonary embolisation..$^{23}$ The Rashkind umbrella device (USCI Angiographics, Billerica, Massachusetts) used for closure of the persistently patent ductus arteriosus has also been used to occlude various shunt lesions including systemic to pulmonary collaterals, persistent abnormal venous channels, atrial septal defects after Fontan repair, ventricular septal defects, residual aortopulmonary windows, and Pott's shunts. ${ }^{46}$. We report the clinical use of the umbrella occluder for transcatheter closure of modified Blalock-Taussig shunts in three patients and describe a modification to the delivery system.

\section{Case reports}

CASE 1

The first person was born with tricuspid atresia, ventriculoarterial concordance, a hypoplastic right ventricle, a ventricular septal defect, and pulmonary stenosis. Balloon atrial septostomy was performed before she was a month old and later a modified right polytetrafluoroethylene (Gore-Tex) BlalockTaussig shunt was constructed when she was a year old. When she was four a cardiac catheterisation showed a restrictive ventricular septal defect. This was surgically enlarged and the right ventricular outflow tract was reconstructed. When she was six years old a Fontan procedure was performed but the BlalockTaussig shunt was not ligated. A persistent continuous murmur in the right infraclavicular region was present and a repeat catheterisation when she was eight years old confirmed that the right shunt was patent. Transcatheter closure was performed transvenously from the right femoral vein with a long $11 \mathrm{~F}$ sheath positioned across the shunt and a $17 \mathrm{~mm}$ Rashkind occluding device. No residual flow was demonstrated on the angiogram.

CASE 2

The second patient was born with tricuspid atresia, ventriculoarterial concordance, ventricular septal defect, pulmonary atresia, and hypoplastic right ventricle and pulmonary arteries. A balloon atrial septostomy was performed in the newborn period followed by a modified right Gore-Tex Blalock-Taussig shunt. At four years in view of persistent pulmonary artery hypoplasia a modified lef Blalock-Taussig shunt was created followed at six years of age by a bi-directional Glenn anastomosis, bilateral pulmonary arterioplasties, and ligation of the right-sided shunt. At cardiac catheterisation at seven years of age the aortic saturation was $88 \%$ in room air and the pressures in the Glenn shunt (mean $=19$ $\mathrm{mm} \mathrm{Hg}$ ) and distal left pulmonary artery (mean $=16 \mathrm{~mm} \mathrm{Hg}$ ) were raised. An attempt at coil embolisation of the left-sided shunt was unsuccessful because the coil could not be stabilised in a good position. Subsequently, a long $8 \mathrm{~F}$ sheath was passed through the right internal jugular vein and guided over an exchange wire into the mid-portion of the shunt where a 12 mm Rashkind occluding device was implanted successfully (fig 1). Digital subtraction angiography after occlusion showed only minimal residual flow and at six month follow-up no washout from the shunt was noted.

CASE 3

The third patient had pulmonary atresia with intact ventricular septum, a diminutive right ventricle, dysplastic tricuspid valve, patent foramen ovale, and a large patent ductus arteriosus. After a balloon atrial septostomy on day 1 a $5 \mathrm{~mm}$ modified Gore-Tex BlalockTaussig shunt and transarterial pulmonary valvotomy were constructed. At 1.5 years a balloon pulmonary valvotomy and angioplasty of the left pulmonary artery were required. Shortly afterwards complete repair was attempted but not tolerated: the atrial septum had to be partly re-opened and flow through the Blalock-Taussig shunt had to be re-established. Nine months later a bi-directional Glenn shunt was constructed and when he was 4.5 years old catheterisation confirmed haemodynamic stability with transient balloon occlusion of the atrial defect and left BlalockTaussig shunt. A long $7 \mathrm{~F}$ sheath positioned \\ Paediatrics, Division \\ Hospital for Sick \\ Ontario, Canada \\ C Houde \\ E M Zahn
} . 
Figure 1 (A)

Angiogram of the Blalock

Taussig shunt through the arterial catheter. A long sheath (arrow head) is positioned through the right internal jugular vein into the pulmonary end of the shunt. (B) Angiogram after occlusion with a 12 mm device (arrow) shows only minimal residual shunting.
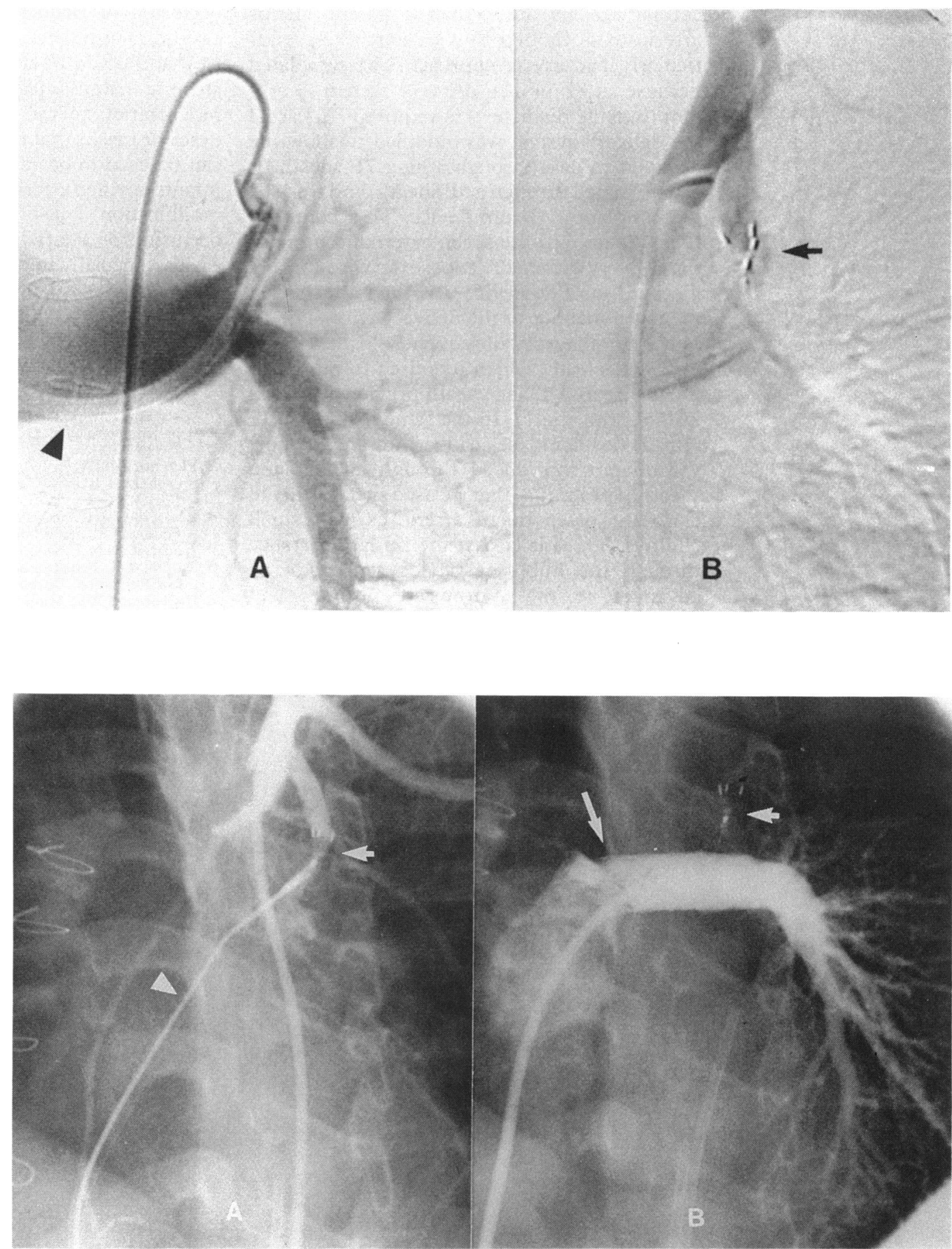

anterogradely in the left shunt was successfully used to position a $12 \mathrm{~mm}$ double umbrella device loaded on a modified delivery system within the shunt. After embolisation, the proximal left pulmonary artery was dilated and stented (Johnson \& Johnson Interventional Systems Warren, New Jersey) with a $3.4 \times 30$ mm stent that expanded to $12 \mathrm{~mm}$ (fig 2). Two days later his atrial septal defect, which was unsuitable for catheter closure, was surgically repaired. One week after repair echocardiography showed normal tricuspid valve inflow, unobstructed stent flow, and no evidence of continuous flow from the left Blalock-Taussig shunt.

\section{Discussion}

When closure of a Blalock-Taussig shunt is the only procedure required or when surgical ligation of a shunt makes an operation technically more difficult, transcatheter closure could be an alternative option. Coil and balloon embolisation require precision in assessing the size of the coil (or balloon) required for the lumen diameter. Flow control is needed during implantation and the technique is easier if a distal (downstream) stenosis is present within the vessel being embolised.

The Rashkind umbrella device and delivery system have been used in many cases to close a persistently patent ductus arteriosus and several other cardiac lesions. ${ }^{4}$ Complications were rare. ${ }^{7}$ In the past four years we have used this device to embolise three Blalock-Taussig shunts. The technique is simple and requires few manipulations but its ability to occlude 
cardiac lesions other than a patent ductus arteriosus is limited by vascular access, particularly if an arterial approach is contemplated because an $8 \mathrm{~F}$ or $11 \mathrm{~F}$ delivery system ( 3 or 4 $\mathrm{mm}$ (outside diameter)) is required. In case 3 the delivery system was modified to allow the occluder to pass through a long $7 \mathrm{~F}$ sheath (it can be passed through a $6 \mathrm{~F}$ sheath) and we used it to implant a $12 \mathrm{~mm}$ device. To accomplish this we removed the green external coating of the delivery catheter to expose the wire-locking mechanism. The device was then attached in the usual manner to the delivery wire. The 12 $\mathrm{mm}$ umbrella was subsequently loaded into a $6 \mathrm{~F}$ short sheath, which was used to introduce the device into a long sheath previously placed in the shunt (fig 1). In the same manner, a 17 $\mathrm{mm}$ device could be loaded into an $8 \mathrm{~F}$ short sheath and introduced through an $8 \mathrm{~F}$ long sheath, a procedure that we used successfully to close large patent ductus arteriosus in two small children. Once it is past the initial resistance through the hub, the device can easily be advanced to the appropriate position and implanted.

In conclusion, we found that a Rashkind umbrella device was a suitable alternative for occlusion of Blalock-Taussig shunts. It was easy to manipulate, did not require flow control, and could be used in patients with nonstenotic communications. Furthermore, the modification to the delivery system that we describe means that the double umbrella device can be used to occlude extracardiac lesions in $\stackrel{\text { W }}{?}$ infants or when arterial access is required. Such $\frac{T}{\Phi}$ modification also makes transcatheter $\stackrel{\otimes}{\stackrel{N}{2}}$ occlusion of a large patent ductus arteriosus $\underline{.}$. easier, especially in patients weighing less than $\overrightarrow{\vec{F}}$ $10 \mathrm{~kg}$.

1 Lois JF, Gomes AS, Smith DC, Laks H. Systemic-topulmonary collateral vessels and shunts: Treatment with embolization. Radiology 1988;169:671-6.

2 Perry SB, Radtke W, Fellows KE, et al. Coil embolization to occlude aortopulmonary collateral vessels and shunts in 0 patients with congenital heart disease. J Am Coll Cardiol $\overrightarrow{0}$ 1989;13:100-8.

3 Florentine M, Wolfe RR, White RI. Balloon embolization to occlude a Blalock-Taussig shunt. J Am Coll Cardiol 1984;3:200-2.

4 Lock JE, Cockerham JT, Keane JF, Finley JP, Wakely PE, Fellows KE. Transcatheter umbrella closure of congenital heart defects. Circulation 1987;75:593-9.

5 Mullins CE. Pediatric and congenital therapeutic cardiac catheterization. Circulation 1989;79:1153-9.

6 Hellenbrand WE, Mullins CE. Catheter closure of congen- of ital cardiac defects. Cardiology Clinics 1989;7:351-68.

7 Hosking MCK, Benson LN, Musewe N, Dyck J, Freedom 윽 RM. Transcatheter occlusion of the persistently patent ductus arteriosus. Circulation 1991;84:2313-7. 